\title{
QUANTITATIVE DETERMINATION OF GALANTHAMINE AND LYCORINE IN GALANTHUS FOSTERI
}

\author{
() Kaya G. I., Emir A, Sarıkaya B., Onur M. A., Unver Somer N.
}

Department of Pharmacognosy, Faculty of Pharmacy, Ege University, Bornova Izmir 35100, Turkey

Among the 14 taxa and one hybrid of the genus Galanthus growing in Turkey, Galanthus fosteri Baker is distributed mainly in south-and north-central Turkey (1, 2). Galanthamine, the most important alkaloid found in Amaryllidaceae species, is used for the treatmant of Alzheimer's disease (3). Lycorine, a widespread alkaloid found in Amaryllidaceae plants has important biological activities (4). Therefore it is important to quantify these alkaloids in Amaryllidaceae species. In the present study, a reversed-phase high-performance liquid chromatographic method has been used for the quantitative determination of lycorine and galanthamine in G. fosteri. The chromatographic separation was performed using an isocratic system with a mobil phase trifluoroacetic acid-water-acetonitrile (0.01: 92.5: 7.5$)$ and diode array dedector (5). The linearity of the method was studied by injecting five known concentrations of lycorine in the range of $2.5-40 \mu \mathrm{g} / \mathrm{mL}$ and five known concentrations of galanthamine in the range of $1-16 \mu \mathrm{g} / \mathrm{mL}$. The calibration curves for lycorine and galanthamine were determined as $Y=15.6024 x+0.4459$ and $Y=10.8302 x-1.9292$, respectively. The contents of galanthamine in the aerial parts was found to be $0.003 \%$ whereas the amount of the lycorine was found as $0.010 \%$. The contents of galanthamine and lycorine in the bulbs of $G$. fosteri were found to be $0.012 \%$ and $0.035 \%$, respectively.

References: (1) Davis A.P. (2006) The Genus Galanthus-Snowdrops in the Wild, In: Bishop M., Davis A. P., Grimshaw J. (Eds.), Snowdrops, A Monograph of Cultivated Galanthus. Griffin Press Publishing Ltd. Cheltenham. (2) Brickell, C.D. (1984). In: Davis, P. H. (Ed.), Flora of Turkey and the East Aegean Islands, Edinbugh, University Press, Edinburgh, vol. 8., pp. 358-381. (3) Heinrich M. (2010). Galanthamine from Galanthus and other Amaryllidaceae-chemistry and biology based on traditional use. In: The Alkaloids Chemistry and Biology. Editor: Geoffrey Alan Cordell, Elsevier Inc., San Diego. vol. 68, pp. 157-165. (4) Szlàvik, L., Gyuris À, Minàrovits J, Forgo P, Molnàr, J., Hohmann J. (2004) Planta Med 70:871873. (5) Mustafa, N.R., Rhee I. K., Verpoorte R. (2003). J Liq Chromatogr R T 26:3217-3233.

Acknowledgements: This study was financially supported by Ege University Research Fund (09/ECZ/037).

\section{OVERVIEW OF HERBAL MEDICINE/SUPPLEMENTS IN USA}

\section{(c) Khan Ikhlas A.}

National Center for Natural Products Research and Department of Pharmacognosy, School of Pharmacy, The University of Mississippi, MS 38677, U. S.A.

Herbal product studies cannot be considered scientifically valid if the product tested was not authenticated and characterized in order to ensure reproducibility in the manufacturing of the product in question. In the case of botanicals, misidentification of the collected plant, adulteration with other species or contamination with extraneous ingredients are possibilities in which reproducibility may be effected unknown to the manufacturer. Many studies refer to the use of standardized material, but in reality they are referring to chemical standardization. While chemical standardization is important, its utility is limited when the starting material is not well characterized botanically.
Although the resulting studies are sound with respect to the actual product tested, adequate authentication of the product cannot be compared to other products on the market. Also, a comparison of one study to another cannot be made due to inconsistencies in the identity of the botanical matrix. The tools needed for authentication of the field plant material also depend on the plant and process involved. This could be as straightforward as botanical/morphological identification or as elaborate as genetic or chemical profiling. These controls are also critical for the evaluation of pharmacological, toxicological and clinical studies of the botanical supplements. 